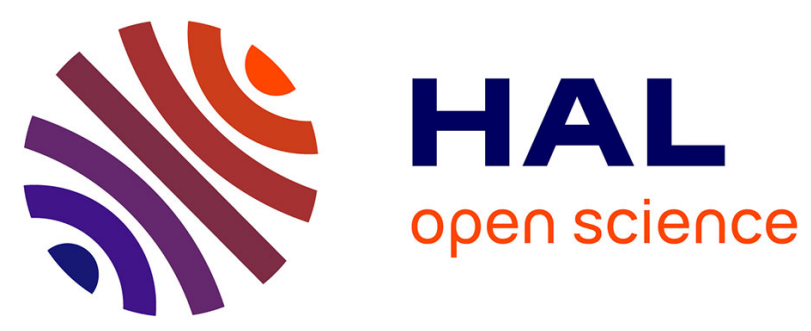

\title{
Handwriting in Children and Adults With Down Syndrome: Developmental Delay or Specific Features?
}

Raphaële Tsao, Eloïse Moy, Jean-Luc Velay, Nicolas Carvalho, Carole Tardif

\section{To cite this version:}

Raphaële Tsao, Elö̈se Moy, Jean-Luc Velay, Nicolas Carvalho, Carole Tardif. Handwriting in Children and Adults With Down Syndrome: Developmental Delay or Specific Features?. American Journal on Intellectual and Developmental Disabilities , 2017, 122 (4), pp.342 - 353. 10.1352/1944-7558122.4.342 . hal-01772022

\section{HAL Id: hal-01772022 \\ https://hal-amu.archives-ouvertes.fr/hal-01772022}

Submitted on 7 May 2018

HAL is a multi-disciplinary open access archive for the deposit and dissemination of scientific research documents, whether they are published or not. The documents may come from teaching and research institutions in France or abroad, or from public or private research centers.
L'archive ouverte pluridisciplinaire HAL, est destinée au dépôt et à la diffusion de documents scientifiques de niveau recherche, publiés ou non, émanant des établissements d'enseignement et de recherche français ou étrangers, des laboratoires publics ou privés. 
R. Tsao, E. Moy, J.L, Velay, N. Carvalho \& C. Tardif

\begin{abstract}
While there is a long history and tradition of behavioral research on basic motor skills in Down syndrome (DS), there has been only limited research on handwriting ability. We analyzed the spatiotemporal features of handwriting produced by children and adults with DS $(n=24)$, and compared their productions with those of comparison groups matched for developmental $(n=24)$ or chronological $(n=24)$ age. Results indicated that the participants with DS performed an alphabet letter-writing task just as efficiently as the children of the same developmental age, in terms of the length, duration and speed of their handwriting, and the number and duration of their pauses. Our study highlights a substantial delay in the stages of writing acquisition.

Keywords: Down syndrome, temporal analysis of handwriting, controlled movement, intra-individual variability, copying task
\end{abstract}

\title{
Introduction
}

The inclusion in ordinary schools of children and adolescents with special educational needs, such as those with Down syndrome (DS), has become a major societal issue for the many countries that have incorporated the principles of UNESCO's 1994 Salamanca Statement in their education policies (WHO, 2011). If they are to benefit from mainstreaming, children with special educational needs need to master a whole set of skills, chief among them handwriting. For children with DS, however, handwriting can be a challenge (Trenholm \& Mirenda, 2006; Turner \& Alborz, 2003), potentially compromising their ability to derive benefit from their education and find employment thereafter. Despite the importance of handwriting at school, it has received limited attention from 
the scientific community. As a result, we have relatively little data about either handwriting quality or the graphomotor control involved in writing tasks. We therefore felt it was important to examine movement control during writing tasks, in order to improve current understanding of the handwriting process in DS.

\section{Is handwriting still a relevant area of research?}

Handwriting is defined as a complex activity that takes many years to master and is constrained by a whole set of processes (Bara \& Gentaz, 2010). It relies on coordination between the higher-level cognitive and linguistic mechanisms (e.g., semantic, syntactic and orthographic) involved in text production, and the lower-level perceptual-motor processes that underlie the programming and execution of handwriting movements (e.g., graphomotricity). Compared with other activities related to written language, such as reading and writing text, handwriting has tended to be neglected by researchers, even though it continues to be extensively used in the classroom (Marr, Cermak, Cohn, \& Henderson, 2003; McHale \& Cermak, 1992). For instance, the 2014 Handwriting Without Tears ${ }^{\circledR}$ survey of 459 American schoolchildren aged $5-11$ years revealed that they spent $25-60 \%$ of their time at school each day writing on paper, compared with just $15-22 \%$ of their time using technology such as tablets, computers and interactive whiteboards. Moreover, recent research has shown that the actual handwriting experience makes a key contribution to the representation and recognition of alphabet letters (James \& Engelhardt, 2012; Longcamp, Zerbato-Poudou, \& Velay, 2005). Graphic transcription may require very little effort from expert writers, but the same is certainly not true for children, especially those with specific pathologies.

\section{Handwriting in children and adults with Down syndrome}

There has been very little handwriting research in the field of intellectual disabilities, and more specifically in DS, whether the focus is on the product or on the cognitive processes involved. Work on literacy development within this population has mainly concentrated on learning to read (for a review, see Kay-Raining Bird \& Chapman, 2012), even though several studies have provided evidence that individuals with DS are quite capable of writing from a young age. Some children with 
DS in the 5- to 9-year age group are able to copy and/or write single letters or familiar words such as their firstname and surname (Trenholm \& Mirenda, 2006; Turner \& Alborz, 2003). Furthermore, when Vaginay (1995) studied a sample of 94 children with DS aged 6-14 years, he found that most of them were able to write several familiar words without a model (e.g., their firstname, maman, papa) from age 10-11 years upwards. These were mostly written in uppercase letters, and two thirds of them were classified as accurate and legible. For longer, more complex utterances (e.g., noun phrases and sentences), success rates were markedly lower. For their part, Trenholm and Mirenda (2006) showed that the vast majority of adults with DS between the ages of 19 and 41 years are capable of writing. This ability can range from writing a single word or a firstname to penning a letter or producing simple answers to questions. In the case study of Françoise, overall IQ $=64$, reported by Rondal (1995), analysis of her written expression skills showed that she was able to compose and transcribe a message. Nevertheless, analysis of her spontaneous production revealed difficulties with punctuation and morphosyntax, while under dictation, she was found to make frequent grammatical errors (e.g., subject-verb agreement mistakes), as well as omissions or insertions of letters or strokes (e.g., temp for temps, solleil for soleil, fètes for fêtes). The author attributed these mistakes to orthographic difficulties, rather than to problems with letter knowledge, as they were not systematically observed during the dictation of simple sentences (e.g., "Les jolies roses sont dans le vase"). In terms of execution, her handwriting was legible, even if some letters were misshapen or had been touched up. Given that analysis of Françoise's written production failed to reveal dysfunctions at any level of handwriting processing, Rondal (1995) concluded that the peripheral (e.g.., motor) components of handwriting in adults with DS are preserved. He reached this conclusion, however, without conducting an actual handwriting analysis, which is why Tsao and colleagues devoted two studies to the quality of handwriting and the movements required to produce it in adults with DS (Tsao, Fartouk, \& Barbier, 2011; Tsao, Velay, Barbier, \& Gombert, 2012), using the Concise Assessment Scale for Children's Handwriting (BHK; Charles, Soppelsa, \& Albaret, 2004). These authors found that the handwriting produced by their DS sample was relatively similar 
to that of a sample of children matched for developmental age (DA), in terms of letter quality (letter formation and legibility) and production speed (number of characters produced within $5 \mathrm{~min}$ ) (Tsao et al., 2011). However, the results with comparison matched for chronological age (CA) revealed significant differences between the two. The handwriting of the adults with DS was of poorer quality, with oversized, irregular and misshapen letters. They appeared to have greater difficulty managing the writing space (e.g., writing in a straight line, leaving a margin on the right), and wrote more slowly. Temporal analysis also failed to reveal any difference between the participants with DS and the DA-matched children in terms of either the number and duration of segments and pauses, or the total duration of the handwriting movements required to produced single letters or familiar words (e.g., papa) (Tsao et al., 2012). Once again, however, comparisons with the CA-matched participants pointed to greater difficulty within the DS group, as it took these participants noticeably longer to copy letters and words. The fact that the adults with DS paused more during the copy task suggests that they generated the letters by juxtaposing tiny segments which, when stuck end to end, formed the strokes needed to make each letter. This in turn suggests that they engaged in retroactive (e.g., during handwriting execution) control, which is the mode observed in typically developing children who are just starting to learn to write (Graham, 2010; Graham, Struck, Santoro, \& Berninger, 2006).The fact that this step-by-step organization has also been reported in studies analyzing reachto-grasp movements implies that the same type of movement planning applies to a whole set of visuomotor tasks (Carvalho \& Vasconcelos, 2011; Elliott, Welsh, Lyons, Hansen, \& Wu, 2006; Kearney \& Gentile, 2003).

Research on handwriting in adults with DS has yet to identify a specific deficit in the spatial organization and control of handwriting production, although it has highlighted a major delay in the stages of writing acquisition. This raises the question of whether similar patterns can be observed in children and adolescent with DS. To date, there have been only two studies in this population. First, Varruza, De Rose, Vicari, and Menghiny (2015) analyzed the various components of handwriting in participants with intellectual disabilities, DS or Williams syndrome. Results indicated that the group 
with DS (e.g., 12 participants aged from 7 to 31), produced similar handwriting (e.g., letter slope and shape, pen pressure) to that of DA-matched participants. However, the authors did not analyze the contribution of DA to handwriting in any of the three groups of participants. Second, the study by Moy, Tardif, and Tsao (2016) focused on the predictive factors for handwriting in adolescents and adults with DS. Of all the factors they studied, fine motor coordination, assessed via the ability to imitate a model's hand or finger positions, emerged as the best predictor of handwriting quality. This factor explained $63 \%$ of the variance in handwriting quality. Finger dexterity, which relies on fine, precise and dissociated movements of the fingers, appears to have a considerable impact on the ability to produce the fine movements required in a writing task. To date, however, there has been no research on the movement control involved in the performance of handwriting tasks by persons with DS. Instead, studies have analyzed handwriting strokes on paper. Virtually none have used a graphic tablet to undertake handwriting analyses, with the exception of Tsao et al. (2012), whose study exclusively involved adults with DS. The purpose of the present study was thus to analyze the spatiotemporal and kinematic aspects of handwriting movements in a writing task featuring letters of varying complexity administered to children and adults with DS. To our knowledge, it is the first study which assessed the influence of DA or CA on handwriting in DS population using statistical analyzes with DA or CA as covariate. We expected the stroke length and duration, handwriting speed, pause number and duration and pen pressure of participants with DS to be similar to those observed for participants matched on DA, but poorer than those recorded among participants matched on CA. The handwriting of individuals with DS could well be characterized by stroke instability, as well as by developmental delay. Intra-individual variability is another variable that could account for handwriting automation difficulties. In particular, the study conducted by Borella, Chicherio, Re, Sensini, and Cornoldi (2011) among children with attention-deficit hyperactivity disorders indicated that the latter's handwriting was more variable than that of their typically developing peers. This research highlighted the usefulness of going beyond the traditional mean analysis and considering intra-individual variability as an indicator in its own right, rather than a mere measurement error. We 
therefore included a measure of intra-individual variability in order to assess whether it could serve as a marker for handwriting difficulties among children and adults with DS.

\section{Method}

\section{Participants}

Our sample comprised 24 adults and children ( 13 male, 11 female) with DS, aged between 10 years and 40 years and 10 months, and two comparison groups with 24 children matched for DA, and 24 adults and children matched for CA (see Table 1 for participants' characteristics). The participants with DS were recruited via the Trisomie 21 France federation. The children and adolescents attended mainstream schools, while the adults either had an ordinary job or else were in sheltered or supported employment. Their developmental age was assessed on Raven's Colored Progressive Matrices (CPM; Raven, Raven, \& Court, 1998). The unselected DA group was made up of children attending kindergarten or elementary school, while the CA group comprised secondary schoolchildren and adult employees. Given the interindividual variability of the DS group in terms of DA and CA, we performed individual matching for CA, DA and sex. In other words, each participant with DS was individually matched with a control of the same sex and the same DA, and a control of the same sex and the same CA. This meant we had three groups to compare. Handedness was assessed during the handwriting task, when the experimenter noted which hand was used. All participants gave their informed consent to take part in this study. This research protocol was approved by the ethics committee of Aix-Marseille University and carried out in accordance with the Declaration of Helsinki. 


\begin{tabular}{|c|c|c|c|}
\hline & \multicolumn{3}{|c|}{ Group } \\
\hline & DS & DA & CA \\
\hline Number & $n=24$ & $n=24$ & $n=24$ \\
\hline No. females (\%) & $11(46)$ & $11(46)$ & $11(46)$ \\
\hline Handedness & $21 \mathrm{R} / 3 \mathrm{~L}$ & $17 \mathrm{R} / 7 \mathrm{~L}$ & $20 \mathrm{R} / 4 \mathrm{~L}$ \\
\hline \multirow[t]{3}{*}{ Mean age in years (range) } & $\begin{array}{l}\mathrm{DA}=5.8 \\
(3.7-9.5)\end{array}$ & & \\
\hline & $C A=20.1$ & 5.8 & 20.3 \\
\hline & $(10.0-40.8)$ & $(3.7-9.2)$ & $(9.9-38.6)$ \\
\hline
\end{tabular}

\section{Procedure}

The task was administered individually in a calm and neutral room. We assessed participants' spontaneous handwriting by asking them to write out single letters of the alphabet. The letters had been selected according to their degree of motor difficulty (Jolly, Huron, \& Gentaz, 2014) and their frequency in the French language (New, Pallier, Ferrand, \& Matos, 2001). To study participants' fluidity of movement, we only chose letters that could be written in a single stroke in cursive. Based on these two criteria, we selected $a, e$ and $s$ as the easy letters (simple and frequent), and $b, f$ and $g$ as the difficult ones (complex and infrequent). All the participants underwent an initial learning trial where the cursive model of the letter was displayed on a computer screen. They then performed five further trials without the model, in a spontaneous writing situation. Each letter they produced was immediately masked, to prevent it from being copied. The instructions were as follows: "Here is a letter we want you to write several times. Now that I have shown it to you, I'm going to hide it. Write the letter in your usual handwriting". To control for a possible effect of order, we counterbalanced the order in which the letters were presented. All the letters were written on a Wacom Intuos 4 graphic tablet with an estimated data transfer rate of 197 points per second (pps) and a resolution of 
around 5080 lines per inch (Ipi). Participants wrote with an inkpen that could deliver 2048 levels of pen pressure, so that we could measure the pressure they would normally exert.

\section{Dependent Measures}

The handwriting on the tablet was recorded and then processed using Ecriture Suite (Gilhodes \& Velay, 2012) software. The software interface is illustrated in Figure 1. Color coding was used to distinguish the actual handwriting (in color) from pen lifts (gray). We measured several dynamic parameters, including stroke length (in $\mathrm{mm}$ ), stroke duration (in s), handwriting speed (in $\mathrm{mm} / \mathrm{s}$ ), and pause number (i.e., zero handwriting speed) and duration. Handwriting strength was measured in terms of mean pen pressure (arbitrary unit) on the sheet of paper.

Figure 1. Presentation of the Ecriture Suite software (Gilhodes \& Velay, 2012) used to record and process participants' handwriting via a graphic tablet. In the lefthand graph, each row corresponds to a stroke or a pen lift. In the righthand image, a color code is used to indicate the different strokes (in color) and the pen lifts between these strokes (in grisgray). The two graphs below indicate changes in pen pressure and handwriting speed over time $(\mathrm{mm} / \mathrm{s})$.

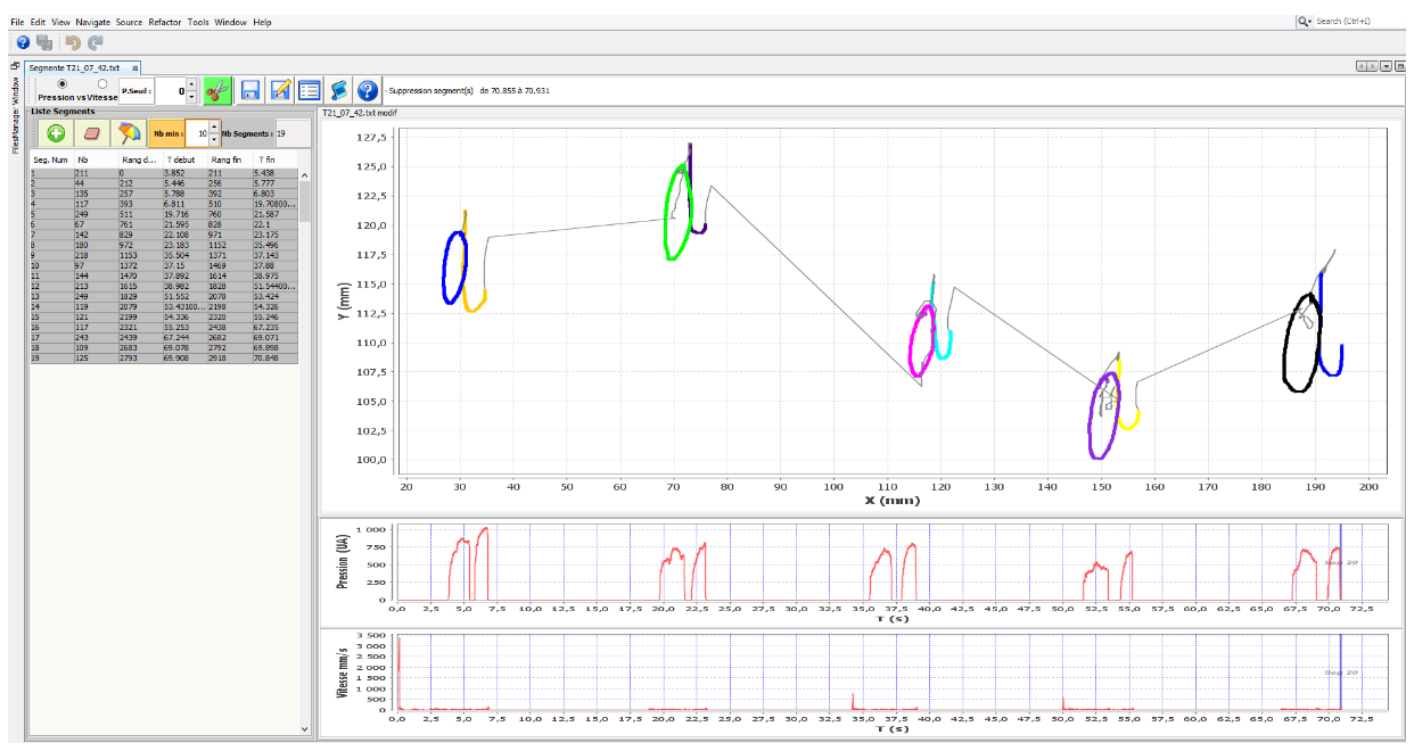

We calculated an individual coefficient of variation (ICV) for each indicator (Borella et al., 2011), by dividing the individual standard deviation by the individual mean. According to Borella and colleagues (2011), this variable provides a reliable means of measuring intra-individual variability. The higher the ICV, the greater the intra-individual variability. We assessed the normality of the variables using the Shapiro-Wilk test. Homogeneity of variance was checked with the Fisher-Snedecor test. We performed repeated-measures (Group * Complexity) and (Group * Trial) analyses of variance (ANOVAs) in order to measure the letters complexity factor and trial factor on 
our six indices (handwriting speed, pause number, pause duration, stroke duration, stroke length, and pen pressure). Tukey's post hoc tests were carried out where appropriate. We assessed the influence of DA or CA using repeated-measures ANCOVAs on ranks, with group (DS vs. DA) as factor, and DA or CA as covariate. To test the direction of the relationship, we ran a Student's $t$ test. The threshold for statistical significance (alpha) was set at $p=0.05$. All the statistical analyses were carried out using R software (Version 3.2.3) and the following functions: Imer from the Ime4 package (Bates, Maechler, Bolker, \& Walker, 2015), Ismeans from the Ismeans package (Lenth, 2015), and sem.model.fits from the piecewiseSEM package (Lefcheck, 2015).

\section{Results}

\section{Stroke length $(\mathrm{mm})$}

The stroke length performances of each group are set out in Table 2. The two-factor (Group * Complexity) ANOVAs revealed a significant main effect of group on stroke length $[F(2,68)=11.63, p$ $<.001]$. Post hoc analyses showed that although stroke length in the DS group did not differ significantly from stroke length in the DA group $(t=61.02, p=.57)$, it was greater than that of the CA group $(t=3.60, p<.01)$. We also observed a significant main effect of letters complexity, as stroke length was greater for difficult letters $[F(1,28)=242.42, p<.001]$. We found a significant effect of the Group $x$ Complexity interaction $[F(2,2069)=13.84, p<.001]$. All three groups used shorter strokes to write the easy letters than to write the difficult ones [(DS: $t=16.29, p<.001$; DA: $t=12.94$, $p<.001$; CA: $t=12.41, p<.001)]$. There was no effect of trial number on stroke length $[F(4,25)=$ $0.059, p=.99$, in any of the groups $F(8,2068)=1.93, p=.052$. The ANCOVAs revealed a significant main effect of DA $[F(1,44)=19.00, p<.001]$, as well as an effect of the Group $\times$ DA interaction $[F(1$, $44)=15.88, p<.001$. Analyses indicated that while stroke length was independent of DA among participants with DS $(t=-0.17, p=.87)$, it decreased with development among controls matched for DA $(t=-7.63, p<.001)$. However, results failed to reveal an effect of CA $[F(1,44)=2.65, p=.11]$, in any of the groups $[F(1,44)=0.0035, p=.95]$. 
With regard to intra-individual variability, Table 3 sets out the mean (standard deviation) overall ICV scores for each of the three groups. There was a significant main effect of group for stroke length $[F(2,68)=27.71, p<0.001]$, as the mean ICV for the DS group did not differ significantly from that of the DA group $(p=0.15)$, but was greater than that of the CA group $(p<0.001)$. Analyses failed to reveal a significant effect of letters complexity $[F(1,4)=1.16, p=0.28]$, and there was no interaction with group $[F(2,423)=1.13, p=0.32]$. The ANCOVAs highlighted a significant main effect of DA $[F(1,44)=13.84, p<0.001]$, but there was no significant interaction with group $[F(1,44)=$ $0.64, p=0.43]$. Variability in stroke length decreased with development $(61=-0.24)$. Results were similar for $\mathrm{CA}[F(1,44)=8.43, p=0.43](B 1=-0.28)$ for all three groups $[F(1,44)=1.14, p=0.29]$.

\section{Stroke duration}

Group performances on stroke duration are set out in Table 2. The ANOVAs revealed a significant main effect of group on stroke duration $[F(2,68)=87.97, p<.001]$. Although the post hoc tests did not reveal a significant difference between the DS and DA groups on stroke duration $(t=-1.41, p=$ .34), it took participants with DS significantly longer to write the letters than it did controls matched for CA $(t=10.77, p<.001)$. We also noted a significant effect of letters complexity $[F(1,28)=115.17$, $p<.001]$, indicating that difficult letters took longer to write. Although the effect of the Group $\mathrm{x}$ Complexity interaction was significant $[F(2,2069)=31.28, p<.001]$, multiple comparisons failed to reveal significant differences between the DS group and the two control groups. In all three groups, stroke duration was shorter for easy letters than for difficult ones [(DS: $t=11.03, p<.001$; DA: $t=$ 11.60, $p<.001$; CA: $t=6.27, p<.001)$ ]. No significant effect of trial number was found on stroke length $F(4,25)=0.61, p=.66$, in any of the groups $[F(8,2069)=1.29, p=.24]$. The ANCOVAs highlighted a significant main effect of DA $[F(1,44)=14.69, \mathrm{p}<.001]$, and a significant interaction with group $[F(1,44)=6.00, p<.05]$. Analyses indicated that while stroke duration was independent of DA in the DS group, $(t=60.75, p=.46)$, it decreased with development among controls matched for DA $(t=-6.32, p<.001)$. There was no significant effect of the CA covariate $[F(1,44)=2.85, p=$ .099], in any of the groups $[F(1,44)=0.0021, p=.96]$. 
The ANOVAs showed a significant main effect of group on ICV for stroke duration $[F(1,44)=$ $6.00, p<0.05]$. The DS group was less variable than the DA group $(p<0.01)$, but more variable than the CA group $(p<0.001)$. Analyses did not reveal a significant effect of letters complexity $[F(1,4)=$ 0.98, $p=0.32]$. There was no Group $x$ Complexity interaction $[F(2,423)=0.33, p=0.72]$. The ANCOVAs highlighted a significant main effect of DA $[F(1,44)=7.31, p<0.01]$. ICV for stroke duration decreased with development $(B 1=-0.23)$ in all three groups $[F(1,44)=0.014, p=0.91]$. There was no significant effect of the CA covariate $[F(1,44)=3.02, p=0.089]$, but a Group $\times$ CA interaction was noted $[F(1,44)=4.70, p<0.05]$. Variability decreased with CA within the DS group $(61=-0.33, p<$ $0.01)$, in contrast to the CA group ( $p=0.77)$.

\section{Handwriting speed $(\mathrm{mm} / \mathrm{s})$}

Handwriting speeds for each group are set out in Table 2. The two-factor ANOVAs revealed a significant effect of group on handwriting speed $[F(2,68)=12.98, p<.001]$. Although the post hoc tests did not show a significant difference between the DS and DA groups on speed $(p=.96)$, participants with DS performed more poorly than controls matched for CA $(p<.001)$. We observed a significant effect of letters complexity $[F(1,28)=47.89, p<.001]$, as well as an effect of the Group $\mathrm{x}$ Complexity interaction, $[F(2,2069)=11.82, p<.001]$. Participants in all three groups wrote the easy letters faster than the difficult ones $(t=6.92, p<.0001)$. The ANOVA failed to reveal a significant effect of trial number on handwriting speed $[F(4,25)=0.57, p=.69]$, for any of the groups $F(8,2069)$ $=0.63, p=.75$. The ANCOVAs did not indicate a significant main effect of DA on handwriting speed $[F(1,43)=2.14, p=.15]$, and there was no interaction with group $[F(1,43)=3.33, p=.075]$. Results were similar for CA $[F(1,44)=0.10, p=.75]$, for all three groups $[F(1,44)=0.0032, p=.96]$.

The ANOVAs revealed a significant effect of group on ICV for handwriting speed $[F(2,68)=$ 28.69, $p<0.001]$. The DS group was less variable than the DA group $(p<0.01)$, but more variable than the CA group $(p<0.001)$. There was no significant main effect of letters complexity $[F(1,4)=$ 0.66, $p=0.42]$, and no significant Group $\times$ Complexity interaction $[F(2,423)=0.15, p=0.86]$. The ANCOVAs showed a significant effect of DA on $\operatorname{ICV}[F(1,44)=8.98, p<0.01]$, as variability in 
handwriting speed declined with DA $(B 1=-0.20)$ for all groups $[F(1,44)=0.24, p=0.63]$. However, they failed to highlight a significant effect of $C A[F(1,44)=4.01, p=0.051]$. There was a significant Group $\times$ CA interaction $[F(1,44)=6.63, p<0.05]$. Variability decreased with CA in the DS group $(61=$ $-0.43, p<0.001)$, but not in the CA group $(p=0.46)$.

\section{Number of pauses}

The numbers of pauses made by each group are set out in Table 2. The ANOVAs indicated a significant main effect of group on pause number $[F(2,68)=32.75, p<.001]$. Although the post hoc tests did not show a significant difference between the DS and DA groups $(t=-2.06, p=.11)$, participants with DS produced more pauses than controls matched for CA $(t=5.79, p<.001)$. We also observed a main effect of letters complexity, indicating that participants made significantly more pauses for difficult letters than for simple ones $[F(1,28)=13.30, p<.01]$. The effect of the Group $\mathrm{x}$ Complexity interaction was significant $[F(2,2069)=9.74, p<.001]$. More pauses were produced by the DS and DA groups when the letters were difficult [(DS: $t=4.46, p<.001 ; \mathrm{DA}: t=3.93, p<.01$ )], whereas there was no significant difference between simple and difficult letters in the CA group ( $t=$ $0.30, p=.99)$. We found no effect of trial number $[F(4,25)=1.31, p=.29]$, in any of the three groups $[F(8,2069)=0.79, p=.62]$. Regarding the effects of the DA and CA covariates, the ANCOVAs failed to reveal a significant effect of either DA $[F(1,44)=3.28, p=.08]$ or $\mathrm{CA}[F(1,44)=0.19, p=.66]$, and there was no significant interaction between either group and DA $[F(1,44)=2.18, p=.15]$ or group and $C A[F(1,44)=0.31, p=.58]$.

The ANOVAs failed to reveal significant main effects of either group $[F(2,68)=0.64, p=0.53]$ or letters complexity on ICV for the number of pauses $[F(1,4)=0.047, p=0.83]$ in any of the three groups $[F(2,423)=0.41, p=0.67]$. The ANCOVAs did not show a significant effect of DA $[F(1,44)=$ 2.20, $p=0.15]$, and there was no significant Group $\times$ DA interaction $[F(1,44)=1.16, p=0.29]$. For the CA covariate, analyses failed to reveal a significant main effect $[F(1,44)=0.27, p=0.61]$, but we found a significant Group x CA interaction $[F(1,44)=5.92, p<0.05]$. ICV was independent of CA in the DS group $(p=0.10)$, whereas it increased in the CA group $(B 1=0.17, p<0.05)$. 


\section{Pause duration}

Pause durations for each group are set out in Table 2. The two-factor ANOVAs (Group * Complexity) highlighted a significant effect of group on pause duration $[F(2,68)=40.12, p<.001]$. Although the post hoc tests did not reveal a significant difference between the DS and DA groups on pause duration ( $t=-2.16, p=.086)$, participants with DS paused for significantly longer than controls matched for CA $(t=6.50, p<.001)$. We also observed an effect of letters complexity, indicating that pause duration was significantly longer for difficult letters $[F(1,28)=12.11, p<.01]$. We found a significant Group $x$ Complexity interaction $[F(2,2069)=12.75, p<.001]$, revealing that the DS and DA groups paused for longer when writing difficult letters [(DS: $t=4.88, p<.001 ;$ DA: $t=3.55, p<.01)$ ], whereas there was no significant difference between simple and difficult letters for the CA group ( $t=$ $-0.17, p=.99)$. Analyses failed to show a significant effect of trial number on pause duration $[F(4,25)$ $=1.66, p=.19]$ in any of the three groups $[F(8,2069)=0.62, p=.76]$. Regarding the DA and CA covariates, the ANCOVAs did not indicate a significant main effect of either $\operatorname{DA}[F(1,44)=1.57, p=$ $.22]$ or $C A[F(1,44)=0.39, p=.53]$, and there was no effect of the interactions between either group and DA $[F(1,44)=1.78, p=.19]$ or group and $C A[F(1,44)=0.29, p=.59]$.

With regard to variability, results did not reveal any significant effect of group on ICV for pause duration $[F(2,68)=0.60, p=0.55]$. There was no significant effect of letters complexity $[F(1,4)$ $=0.0084, p=0.93]$, and no significant Group $\times$ Complexity interaction $[F(2,423)=0.29, p=0.75]$. Regarding the effects of the DA and CA covariates, the ANCOVAs failed to reveal a significant effect of either DA $[F(1,44)=2.92, p=0.094]$ or $C A[F(1,44)=0.097, p=0.76]$, and there was no significant interaction between group and DA $[F(1,44)=0.98, p=0.54]$. Analyses did, however, reveal a significant Group x CA interaction $[F(1,44)=5.21, p<0.05]$. ICV did not differ within either the DS ( $p$ $=0.096)$ or CA $(p=0.47)$ groups.

\section{Pen pressure}

See Table 2 for the pen pressure performances of the three groups. The two-factor (Group * Complexity) ANOVAs did not reveal any significant effect of group on the level of pressure exerted on 
the pen $[F(2,68)=1.60, p=.21]$. They did, however, highlight a significant effect of letters complexity $[F(1,28)=26.03, p<.001]$, indicating that greater pressure was exerted during the production of difficult letters. A significant effect of the Group x Task interaction $[F(2,2069)=40.05, p<.001]$ showed that participants in the DS and DA groups exerted greater pressure when writing difficult letters [(DS: $t=3.61, p<.01$; DA: $t=8.85, p<.001)$ ], whereas no significant difference was found between simple and difficult letters in the CA group $(t=-2.39, p=.17)$. There was no significant effect of trial number on pen pressure $[F(4,25)=0.98, p=.44]$ in any of the groups $[F(8,2069)=$ 1.19, $p=.30]$. Concerning the DA and CA covariates, the ANCOVAs did not reveal significant main effects of either DA $[F(1,44)=0.26, p=.61]$ or CA $[F(1,44)=0.45, p=.51]$, and the interactions between group and DA $[F(1,44)=0.20, p=.65]$, and group and $C A[F(1,44)=0.0042, p=.95]$ were not significant.

The ANOVAs highlighted a significant main effect of group on ICV for pen pressure $[F(2,68)=$ $10.72, p<0.001]$. The DS group did not differ significantly from the DA group $(p=0.23)$, but was more variable than the CA group $(p<0.05)$. Analyses did not reveal a significant effect of letters complexity $[F(1,4)=3.32, p=0.14]$ in any of the three groups $[F(2,423)=0.83, p=0.44]$. The ANOVAs did not indicate any significant effect of $\operatorname{DA}[F(1,44)=3.32, p=0.075]$. There was no significant Group x DA interaction $[F(1,44)=1.23, p=0.27]$. For $C A$, results did not reveal any significant effect of this covariate $[F(1,44)=5.03, p<0.05]$, in that variability did not differ between the DS and CA groups $[F(1,44)=3.04, p=0.088]$.

Table 2. Means (Standard Deviation) for Each Handwriting Measure

\begin{tabular}{|c|c|c|c|c|c|}
\hline \multirow[b]{2}{*}{ Indices } & \multicolumn{3}{|l|}{ Group } & \multicolumn{2}{|c|}{ Post hoc summary } \\
\hline & DS & DA & CA & & \\
\hline \multicolumn{6}{|l|}{ Stroke length (mm) } \\
\hline All letters & $69.76(62.69)$ & 90.33 (94.99) & $36.15(26.03)$ & $\mathrm{DS}=\mathrm{DA}$ & $\mathrm{DS}>\mathrm{CA}$ \\
\hline Easy letters & $45.61(35.81)$ & 73.95 (89.67) & 25.95 (17.17) & $\mathrm{DS}=\mathrm{DA}$ & $\mathrm{DS}>\mathrm{CA}$ \\
\hline Difficult letters & $93.92(73.61)$ & $108.58(97.55)$ & $46.35(29.22)$ & $\mathrm{DS}=\mathrm{DA}$ & $\mathrm{DS}>\mathrm{CA}$ \\
\hline
\end{tabular}




\begin{tabular}{|c|c|c|c|c|c|}
\hline \multicolumn{6}{|l|}{ Stroke duration (s) } \\
\hline All letters & $2.54(1.86)$ & $3.01(2.68)$ & $0.65(0.36)$ & $\mathrm{DS}=\mathrm{DA}$ & $\mathrm{DS}>\mathrm{CA}$ \\
\hline Easy letters & $1.90(1.11)$ & $2.32(1.82)$ & $0.54(0.21)$ & $\mathrm{DS}=\mathrm{DA}$ & $\mathrm{DS}>\mathrm{CA}$ \\
\hline Difficult letters & $3.17(2.21)$ & $3.79(3.23)$ & $0.76(0.44)$ & $\mathrm{DS}=\mathrm{DA}$ & $\mathrm{DS}>\mathrm{CA}$ \\
\hline \multicolumn{6}{|c|}{ Handwriting speed (mm/s) } \\
\hline All letters & $33.97(30.6)$ & $33.54(28.44)$ & $55.01(25.03)$ & $\mathrm{DS}=\mathrm{DA}$ & $\mathrm{DS}<\mathrm{CA}$ \\
\hline Easy letters & $29.32(27.2)$ & $32.57(27.73)$ & $47.23(20.24)$ & $\mathrm{DS}=\mathrm{DA}$ & $\mathrm{DS}<\mathrm{CA}$ \\
\hline Difficult letters & $38.63(33.04)$ & $34.62(29.22)$ & $62.79(26.9)$ & $\mathrm{DS}=\mathrm{DA}$ & $\mathrm{DS}<\mathrm{CA}$ \\
\hline \multicolumn{6}{|l|}{ Number of pauses } \\
\hline All letters & $2.51(4.24)$ & $4.63(9.72)$ & $0.49(0.79)$ & $\mathrm{DS}=\mathrm{DA}$ & $\mathrm{DS}>\mathrm{CA}$ \\
\hline Easy letters & $1.87(2.6)$ & $3.34(8.07)$ & $0.47(0.71)$ & $\mathrm{DS}=\mathrm{DA}$ & $\mathrm{DS}>\mathrm{CA}$ \\
\hline Difficult letters & $3.15(5.34)$ & 6.09 (11.13) & $0.52(0.87)$ & $\mathrm{DS}=\mathrm{DA}$ & $\mathrm{DS}>\mathrm{CA}$ \\
\hline \multicolumn{6}{|l|}{ Duration of pauses (s) } \\
\hline All letters & $0.13(0.55)$ & $0.25(0.62)$ & $0.01(0.08)$ & $\mathrm{DS}=\mathrm{DA}$ & $\mathrm{DS}>\mathrm{CA}$ \\
\hline Easy letters & $0.07(0.13)$ & $0.16(0.38)$ & $0.01(0.03)$ & $\mathrm{DS}=\mathrm{DA}$ & $\mathrm{DS}>\mathrm{CA}$ \\
\hline Difficult letters & $0.20(0.77)$ & $0.34(0.79)$ & $0.01(0.1)$ & $\mathrm{DS}=\mathrm{DA}$ & $D S>C A$ \\
\hline \multicolumn{6}{|l|}{ Pen pressure } \\
\hline All letters & $563.2(201.68)$ & 638.1 (191.99) & 559.3 (171.37) & $\mathrm{DS}=\mathrm{DA}$ & $\mathrm{DS}=\mathrm{CA}$ \\
\hline Easy letters & $548.6(206.31)$ & $602.9(200.05)$ & $572.3(175.85)$ & $\mathrm{DS}=\mathrm{DA}$ & $\mathrm{DS}=\mathrm{CA}$ \\
\hline Difficult letters & 577.9 (196.09) & $677.3(174.75)$ & $546.3(166.01)$ & $\mathrm{DS}=\mathrm{DA}$ & $\mathrm{DS}=\mathrm{CA}$ \\
\hline
\end{tabular}

Note. DS = Down syndrome; $\mathrm{CA}=$ chronological age; $\mathrm{DA}=$ developmental age.

Table 3. Mean (Standard Deviation) Intra-Individual Variation for Each Handwriting Measure

\begin{tabular}{|c|c|c|c|c|c|}
\hline \multirow[b]{2}{*}{ Indices } & \multicolumn{3}{|l|}{ Group } & \multicolumn{2}{|c|}{ Post hoc summary } \\
\hline & DS & DA & CA & & \\
\hline \multicolumn{6}{|c|}{ ICV for stroke length (mm) } \\
\hline All letters & $0.18(0.16)$ & $0.20(0.21)$ & $0.08(0.04)$ & $\mathrm{DS}=\mathrm{DA}$ & $\mathrm{DS}>\mathrm{CA}$ \\
\hline Easy letters & $0.17(0.18)$ & $0.21(0.23)$ & $0.09(0.05)$ & $\mathrm{DS}=\mathrm{DA}$ & $\mathrm{DS}>\mathrm{CA}$ \\
\hline Difficult letters & $0.18(0.15)$ & $0.20(0.20)$ & $0.07(0.04)$ & $\mathrm{DS}=\mathrm{DA}$ & $\mathrm{DS}>\mathrm{CA}$ \\
\hline \multicolumn{6}{|c|}{ ICV for stroke duration (s) } \\
\hline All letters & $0.19(0.15)$ & $0.26(0.23)$ & $0.10(0.08)$ & $\mathrm{DS}<\mathrm{DA}$ & $\mathrm{DS}>\mathrm{CA}$ \\
\hline
\end{tabular}




\begin{tabular}{|c|c|c|c|c|c|}
\hline Easy letters & $0.20(0.15)$ & $0.25(0.18)$ & $0.10(0.06)$ & $\mathrm{DS}=\mathrm{DA}$ & $\mathrm{DS}>\mathrm{CA}$ \\
\hline Difficult letters & $0.19(0.15)$ & $0.27(0.27)$ & $0.10(0.10)$ & $\mathrm{DS}<\mathrm{DA}$ & $\mathrm{DS}>\mathrm{CA}$ \\
\hline \multicolumn{6}{|c|}{ ICV for handwriting speed $(\mathrm{mm} / \mathrm{s})$} \\
\hline All letters & $0.16(0.11)$ & $0.21(0.15)$ & $0.10(0.06)$ & $\mathrm{DS}<\mathrm{DA}$ & $\mathrm{DS}>\mathrm{CA}$ \\
\hline Easy letters & $0.17(0.12)$ & $0.21(0.15)$ & $0.10(0.06)$ & $\mathrm{DS}<\mathrm{DA}$ & $\mathrm{DS}>\mathrm{CA}$ \\
\hline Difficult letters & $0.16(0.09)$ & $0.20(0.16)$ & $0.10(0.06)$ & $\mathrm{DS}=\mathrm{DA}$ & $\mathrm{DS}<\mathrm{CA}$ \\
\hline \multicolumn{6}{|c|}{ ICV for number of pauses } \\
\hline All letters & $0.77(0.52)$ & $0.73(0.52)$ & $0.95(0.82)$ & $\mathrm{DS}=\mathrm{DA}$ & $\mathrm{DS}=\mathrm{CA}$ \\
\hline Easy letters & $0.81(0.60)$ & $0.73(0.52)$ & $0.96(0.85)$ & $\mathrm{DS}=\mathrm{DA}$ & $\mathrm{DS}=\mathrm{CA}$ \\
\hline Difficult letters & $0.73(0.42)$ & $0.73(0.52)$ & $0.93(0.79)$ & $\mathrm{DS}=\mathrm{DA}$ & $\mathrm{DS}=\mathrm{CA}$ \\
\hline \multicolumn{6}{|c|}{ ICV for duration of pauses (s) } \\
\hline All letters & $0.92(0.54)$ & $0.87(0.59)$ & $1.04(0.83)$ & $\mathrm{DS}=\mathrm{DA}$ & $\mathrm{DS}=\mathrm{CA}$ \\
\hline Easy letters & $0.96(0.62)$ & $0.88(0.58)$ & $1.04(0.83)$ & $\mathrm{DS}=\mathrm{DA}$ & $\mathrm{DS}=\mathrm{CA}$ \\
\hline Difficult letters & $0.87(0.46)$ & $0.86(0.61)$ & $1.04(0.82)$ & $\mathrm{DS}=\mathrm{DA}$ & $\mathrm{DS}=\mathrm{CA}$ \\
\hline \multicolumn{6}{|l|}{ ICV for pen pressure } \\
\hline All letters & $0.13(0.12)$ & $0.13(0.11)$ & $0.08(0.05)$ & $D S=D A$ & $\mathrm{DS}>\mathrm{CA}$ \\
\hline Easy letters & $0.15(0.14)$ & $0.15(0.10)$ & $0.08(0.05)$ & $\mathrm{DS}=\mathrm{DA}$ & $\mathrm{DS}>\mathrm{CA}$ \\
\hline Difficult letters & $0.12(0.11)$ & $0.12(0.11)$ & $0.08(0.05)$ & $\mathrm{DS}=\mathrm{DA}$ & $\mathrm{DS}=\mathrm{CA}$ \\
\hline
\end{tabular}

Note. $\mathrm{DS}=$ Down syndrome; CA = chronological age; DA = developmental age; ICV = individual coefficient of variation.

\section{Discussion}

\section{Delay in handwriting in DS}

The aim of the present study was to ascertain whether the handwriting skills of individuals with DS are characterized by specific processes, or by processes equivalent to those observed in typical controls matched for DA. When we administered an alphabet letter-writing task to children and adults with DS and controls matched for DA or CA, analysis of the six spatiotemporal indices we measured showed that the DS group was just as efficient as the comparison group of children matched for DA. We failed to find any significant difference between these two groups of the same 
DA on handwriting speed, pause number, pause duration, stroke duration or stroke length. The spatiotemporal skills required for handwriting seem to be in line with the DA, revealing no specific deficit. These two groups exhibited a similar mode of movement control, in that they relied on retroactive control (e.g. feedback during handwriting execution), reflected in a slow handwriting speed and oversized letters (Bara \& Gentaz, 2010). Confirming the limited research findings in this area (Tsao et al., 2011, 2012; Verruza et al., 2015), our results argue in favor of a developmental delay in writing acquisition in children and adults with DS. We observed an effect of DA on several of our indices, including stroke duration and stroke length. Interestingly, the latter decreased across development among the typical children, but were independent of DA in the DS group. In other words, the size of the letters and the time it took to write them did not change with development among participants with DS. Comparisons with CA-matched controls showed that the DS group performed more poorly on every index except pen pressure. Even though the children and adults with DS wrote more slowly and with larger letters than controls matched for CA, they exerted the same amount of pen pressure. The fact that the components of handwriting in DS did not improve with DA or CA, can probably be explained by the characteristics of our study sample, as the experimental group was mostly made up of adolescents and adults with DS. We can also note that the means of all our measures were higher for the DS group than for the DA group, even if these differences were not significant. The life experiences of our participants with DS, in particular their degree of familiarity with writing tasks, doubtlessly helped to improve their performances.

The most probable explanation for the absence of an effect on our indices is that their writing abilities were relatively automatized, especially when it came to producing individual letters.

To check the stability of the patterns we included letters of varying complexity in the writing task and administered several trials. Once again, our data highlighted behavioral similarities between the DS and DA groups. We observed a significant effect of task, as producing the difficult letters proved to be more costly in handwriting speed, pause number and duration, and pen pressure for both participants with DS and unselected DA-matched controls. No effect of letters complexity was 
observed in the CA group, who exhibited comparable response profiles whatever type of letter they had to write. There was no effect of trial number, in that indices did not differ from one trial to another for any of the three groups. The ICV analysis showed that the letter strokes produced by the children and adults with DS were no more variable than those produced by their typically developing DA-matched peers, even in the case of complex letters. Indeed, their handwriting speed and stroke duration were less variable than those of the DA-matched controls. It may be that their life experiences, and in particular repetition of handwriting exercises, improved the stability of their movements, especially in terms of stroke duration and handwriting speed. Comparisons with CAmatched controls nonetheless indicated that their handwriting was more variable, except for the pause number and duration indicators. As the participants with DS were characterized by stable graphomotor performances across the trials, intra-individual variability cannot be said to be a feature of their handwriting execution, as it has been in populations with attention-deficit hyperactivity disorders (Borella et al., 2011). Taken together, the results of the current study of handwriting in children and adults with DS do not point to any specific deficit in the programming or execution of handwriting. These data therefore support the hypothesis of a similar developmental sequence and structure, as previously observed with drawing tasks (Barrett \& Eames, 1996; Detable \& Vinter, 2003, Tsao \& Mellier, 2005).

\section{Conclusion and futures research}

By focusing not on stroke quality but on the analysis of movement control, we were able to highlight similarities between typically developing participants and those with DS, in terms of the cognitive processes involved in a writing task. The relatively proficient handwriting skills of the children and adults with DS should encourage education professionals to pursue and reinforce the teaching of handwriting to children and adolescents with DS who attend school. Recent research has shown that the hand that writes contributes to the construction of representations of written language. More specifically, behavioral and brain imaging data show that handwriting movements play a key role in the representation and recognition of letters of the alphabet (James \& Engelhardt, 2012; Longcamp, 
Zerbato-Poudou, \& Velay, 2005). Despite the absence of research measuring the impact of rehabilitation on handwriting in individuals with DS, similarities in their graphomotor execution to comparison group matched on DA suggest that techniques tested among typically developing children (Bara \& Gentaz, 2010) would be just as beneficial for children with DS. In conclusion, we would like to stress that far more studies still need to be conducted if we are to gain a clearer understanding of all the aspects involved in the study of handwriting in individuals with DS. In particular, following the example of work with typically developing children, more research is required on the interactions between linguistic (central) and graphomotor (peripheral) processes in children and adults with DS, in order to establish the latter's role in written production. The research undertaken by Berninger and colleagues (for a review, see Berninger, 2009) has highlighted the high cognitive cost of graphic transcription for children, as well as the way it interferes with the processes of constructing and generating written text. To end with, we believe it is crucial to focus research on methods for teaching writing, in order to support the schooling and learning of children and adults with DS. Many studies have identified a DS-specific phenotype characterized by a language deficit but relatively intact visuospatial abilities. Articles attempting to describe this phenotype increasingly frequently refer to the notion of strengths as well as weaknesses (Silverman, 2007; Fidler, Philofsky \& Fidler, 2007), in acknowledgement of their importance for the design and planning of care packages and interventions (Duanhauer \& Fidler, 2011). To this end, it would be worthwhile measuring the impact of teaching methods based on the visual perception of the letters and memorization, in order to help children with DS automatize their handwriting movements. Moy et al. (2016) highlighted the major contribution of fine motor coordination to handwriting quality among children and adults with DS. It would be useful to extend their research by examining how rehabilitation targeting finger dexterity could improve handwriting. Given the high stakes involved for anyone learning to write, it is surely vital for more studies to be carried out on handwriting, especially among children with disabilities. 


\section{References}

American Psychiatric Association (2013). Diagnostic and statistical manual of mental disorders (5th ed.). Washington, DC: American Psychiatric Association.

Bara, F., \& Gentaz, E. (2010). Apprendre à tracer les lettres? Une Revue Critique. Psychologie Française, 55, 129-144.

Barrett, M. D., \& Eames, K. (1996). Sequential developments in children's human figure drawings. British Journal of Developmental Psychology, 14, 219-236.

Bates, B., Maechler, M., Bolker, B., \& Walker, S. (2015). Linear mixed-effects models using 'Eigen' and S4. R package version 1.1-10. Retrieved from: http://CRAN.R-project.org/package=Ime4

Borella, E., Chicherio, C., Re, A. M., Sensini, V., \& Cornoldi, C. (2011). Increased intraindividual variability is a marker of ADHD but also of dyslexia: A study on handwriting. Brain and Cognition, 77(1), 33-39.

Carvalho, R.L., \& Vasconcelos, D.A. (2011). Motor behavior in Down syndrome: Atypical sensorimotor control. In S. Dey (Ed). Prenatal diagnosis and screening for Down syndrome (pp. 3342). Croatia: In Tech.

Charles, M., Soppelsa, R., \& Albaret, J.M. (2003). BHK -Échelle d'évaluation rapide de l'écriture chez l'enfant. Paris: Éditions et Applications Psychologiques.

Cornhill, H., \& Case-Smith, J. (1996). Factors that relate to good and poor handwriting. American Journal of Occupational Therapy, 50(9), 732-739.

Daunhauer, L.A., Fidler, D.J. (2011). The Down syndrome behavioral phenotype: Implications for Practice and Research in Occupational Therapy. Occupational Therapy In Health Care, 25(1), 7-25.

Detable, C., \& Vinter, A. (2003). Les activités graphiques d'enfants et d'adolescents présentant un retard mental: Etude du respect d'une règle syntaxique. European RReview of Applied Psychology, 53(3/4), 179-188. 
Elliott, D., Welsh, T. N., Lyons, J., Hansen, S., \& Wu, M. (2006). The visual regulation of goal-directed reaching movements in adults with Williams syndrome, Down syndrome, and other developmental delays. Motor control, 10(1), 34-54.

Fidler, D. J., Philofsky, A., \& Hepburn, S. L. (2007). Language phenotypes and intervention planning: Bridging research and practice. Mental Retardation and Developmental Disabilities Research Reviews, 13(1), 47-57.

Graham, S. (2010). Want to improve children's writing: Don't neglect their handwriting. American Educator, 33(4), 20-40.

Graham, S., Struck, M., Santoro, J., \& Berninger,V.W. (2006). Dimensions of good and poor handwriting legibility in first and second graders: Motor programs, visual-spatial arrangement, and letter formation parameter setting. Developmental Neuropsychology, 29, 43-60.

Handwriting Without Tears (2014). Research review [Data file]. Retrieved from https://www.hwtears.com/files/HWT\%20Research\%20Review.pdf

James, K. H., \& Engelhardt, L. (2012). The effects of handwriting experience on functional brain development in pre-literate children. Trends in neuroscience and education, 1(1), 32-42.

Jolly, C., Huron, C., \& Gentaz, E. (2014). A one-year survey of cursive letter handwriting in a French second-grade child with developmental coordination disorder. L'Année psychologique, 114(03), 421-445.

Kay-Raining Bird, E., \& Chapman, R.S. (2012). Literacy development in childhood, adolescence and young adulthood in persons with Down syndrome. In J. A. Burack, R. M. Hodapp, G. Jarocci \& E. Zigler (Eds). The Oxford handbook of intellectual disability and development (pp. 184-199). New York: Oxford University Press. 
Kearney, K., \& Gentile, A. M. (2003). Prehension in young children with Down syndrome. Acta Psychologica, 112(1), 3-16.

Lefcheck, J. (2015). Piecewise structural equation modeling. R package version 1.0.0. Retrieved from: http://CRAN.R-project.org/package=piecewiseSEM

Lenth, R. (2015). Least-squares means. R package version 2.21-1. Retrieved from: http://CRAN.Rproject.org/package=Ismeans.

Longcamp M., Zerbato-Poudou M. T., \& Velay J. L. (2005) The influence of writing practice on letter recognition in preschool children: a comparison between handwriting and typing. Acta Psychologica, 119(1), 67-79.

Marr, D., Cermak, S., Cohn, E. S., \& Henderson, A. (2003). Fine motor activities in Head Start and kindergarten classrooms. American Journal of Occupational Therapy, 57(5), 550-557.

McHale, K., \& Cermak, S. (1992). Fine motor activities in elementary school: Preliminary findings and provisional implications for children with fine motor problems. American Journal of Occupational Therapy, 46, 898-903.

Moy, E., Tardif, C., \& Tsao, R. (2016). Predictors of handwriting in adolescents and adults with Down syndrome. International Journal of Disability, Development and Education. http://doi.org/10.1080/1034912X.2016.1183769

New B., Pallier C., Ferrand L., Matos R. (2001) Une base de données lexicales du français contemporain sur Internet: LEXIQU., L'Année Psychologique, 101, 447-462.

Raven, J., Raven, J. C., \& Court, J. H. (1998). Manual for Raven's Progressive Matrices and Vocabulary Scales. Section 2: The Coloured Progressive Matrices. Oxford: Oxford Psychologists Press/San Antonio, TX: The Psychological Corporation. 
Rondal, J. A. (1995). Exceptional language development in Down syndrome: Implications for the cognition-language relationship. Cambridge, MA: Cambridge University Press.

Silverman, W· (2007). Down syndrome: Cognitive phenotype. Mental Retardation and Developmental Disabilities Research Reviews, 13(3), 228-236.

Trenholm, B., \& Mirenda, P. (2006). Home and community literacy experiences of individuals with Down syndrome. Down Syndrome Research and Practice, 10, 30-40.

Tsao, R., \& Mellier, D. (2005). Étude des habiletés graphomotrices chez l'enfant et l'adulte porteurs de trisomie 21: Approche développementale et comparative. Neuropsychiatrie de l'Enfance et de l'Adolescence, 53(8), 401-406.

Tsao, R., Fartoukh, M., \& Barbier, M.L. (2011). Handwriting in adults with Down syndrome. Journal of Intellectual \& Developmental Disability, 36(1), 20-26.

Tsao, R., Velay, J.-L., Barbier, M.L., \& Gombert, A. (2012). Étude de l'écriture chez des adultes porteurs de trisomie 21. Revue Francophone de La Déficience Intellectuelle, 23, 22-33.

Turner, S., \& Alborz, A. (2003). Academic attainments of children with Down's syndrome: A longitudinal study. British Journal of Educational Psychology, 73, 563-583.

Vaginay, D. (1995). Proceedings from FAIT 21: Journées nationales et européennes sur la trisomie 21: Trisomie 21 et Intégration. Saint-Etienne, France.

Van Hoorn, J. F., Maathuis, C. G., Peters, L. H., \& Hadders-Algra, M. (2010). Handwriting, visuomotor integration, and neurological condition at school age. Developmental Medicine and Child Neurology, 52(10), 941.

Varuzza, C., De Rose, P., Vicari, S., \& Menghini, D. (2015). Writing abilities in intellectual disabilities: A comparison between Down and Williams syndrome. Research in Developmental Disabilities, 37, $135-142$. 
World Health Organization (2011). World Report on Disability. Retrieved from:

http://www.who.int/disabilities/world_report/2011/report.pdf?ua=1 